Souza, M.A.; Medina, J. Parque Estadual dos Três Picos: um lugar especial para as atividades de geoturismo e Ecoturismo na Serra do Mar fluminense. Anais do VIII Congresso Nacional de Ecoturismo e do IV Encontro Interdisciplinar de Ecoturismo em Unidades de Conservação. Revista Brasileira de Ecoturismo, São Paulo, v.4, n.4, 2011, p. 530.

\title{
PARQUE ESTADUAL DOS TRÊS PICOS: UM LUGAR ESPECIAL PARA AS ATIVIDADES DE GEOTURISMO E ECOTURISMO NA SERRA DO MAR FLUMINENSE
}

\author{
Maria Aparecida de Souza*, Jorge Medina** \\ *Universidade do Estado do Rio de Janeiro, ** Guia de turismo
}

E-mails: mariaaparecidade.souza@gmail.com, medinaecoturismo@hotmail.com

Na Região Serrana, no Estado do Rio de Janeiro, foi criada a Unidade de Conservação de Proteção Integral Parque Estadual dos Três Picos. Sua formação física apresenta-se de forma significativa na composição de paisagens e ambientes de exótica e espetacular beleza cênica. Esta também contribuiu na formação de uma rica biodiversidade no domínio de Mata Atlântica. O uso público desta unidade de conservação destina-se essencialmente às atividades de ecoturismo nas diversas trilhas, cachoeiras, observação de pássaros e no montanhismo. Este trabalho tem como objetivo identificar, analisar e promover atividades de geoturismo e ecoturismo na área, buscando-se junto ao visitante a sensibilização e a interpretação dos diversos cenários existentes. A metodologia utilizada foi revisão de bibliografia pertinente ao tema, trabalho de campo, e a observação e análise de locais e trilhas onde há possibilidade de desenvolvimento dessas atividades. tendo como base a educação ambiental. Busca-se como resultado o melhor uso público combinando atividades relacionadas ao geoturismo e ao ecoturismo.

Palavras-chave: Geoturismo; Ecoturismo; Unidade de Conservação; Educação Ambiental 